Viewpoint

\title{
Harmonization of renewable electricity feed-in laws: A comment
}

\author{
Patrik Söderholm \\ Economics Unit, Lulea University of Technology, 97187 Luleå, Sweden \\ Received 30 November 2007; accepted 3 December 2007 \\ Available online 9 January 2008
}

\begin{abstract}
This comment aims at critically analyzing some of the economic efficiency issues that are raised in the paper by Muñoz et al. [2007. Harmonization of renewable electricity feed-in laws in the European Union. Energy Policy 35, 3104-3114] on the harmonization of feedin law schemes for renewable electricity in the European Union. We comment on the choice between green certificate systems and feed-in laws, but pay particular attention to the implementation and design of a harmonized feed-in law scheme. In the comment we argue first that the approach suggested by Muñoz et al. tends to downplay many of the practical difficulties in assessing the real costs facing investors in renewable electricity, not the least since the presence of regulatory uncertainty about the marginal costs of renewable electricity may be essential for the choice between different support systems. Concerning the benefit side of renewable electricity promotion, the Muñoz et al. (2007) paper builds on an interpretation of the EU Renewables Directive that provides plenty of room for national priorities and that therefore essentially implies that harmonized support premiums per se are of little value. We argue instead that a harmonized system should primarily address the international spillover effects from renewable electricity promotion, not the least those related to improved security of supply in Europe. There exists then a strong case for disregarding the specific national benefits of renewable electricity production in the design of harmonized support systems, and for instead considering international-perhaps at the start bilateral-policy support coordination based on entirely uniform support levels.
\end{abstract}

(C) 2007 Elsevier Ltd. All rights reserved.

Keywords: Feed-in laws; Renewable electricity; Harmonization

\section{Introduction}

Different public support mechanisms are still necessary for future market penetration of renewable energy sources in the European Union (and elsewhere). For the electricity sector, the EU Renewables (RES-E) Directive (2001/77/ EC) plays a key role in promoting renewable electric power generation in Europe. The RES-E Directive outlines quantitative goals for the development of renewable electricity in each country until the year 2010, but it also provides substantial freedom on the parts of national governments to select the policy instruments needed to fulfill these goals. This has left the European landscape of renewable energy policy with a wide array of different support systems and resulting price premiums to the producers of green electricity (e.g., Midttun and Koefoed, 2003; European Commission, 2005). Still, the two most

E-mail address: patrik.soderholm@1tu.se commonly used support systems are feed-in laws and green electricity certificates. While the former involves an obligation on the part of electricity retailers to purchase whatever quantity of green electricity that is supplied at a given price (over and above the electricity market price), the latter is in most cases an obligation for retailers to purchase eligible green electricity in an amount equal to a given share of their total electricity sale.

Just as the internalization of carbon dioxide allowance markets opens up for the possibility to achieve carbon emissions reductions cost-effectively, harmonization of national support systems could, it is argued, constitute one way of complying with the European Union's goal for increased renewable electricity at a minimum overall cost to society. Several simulation studies also show that harmonized support levels can yield substantial cost savings (e.g., Voogt et al., 2001; del Rio, 2005; Huber et al., 2006). Article 4 of the RES-E Directive opens up for the possibility to create a common community framework 
for the public support of renewable electricity. Late in December 2005, however, the Commission decided to postpone the decision on such a framework (European Commission, 2005). One reason was that it was considered too early to assess the pros and cons of different support schemes, not the least given the so far relatively short history of some of the support systems such as green certificates. Instead the Commission stressed the need to make the existing national systems more efficient, not the least by improving policy stability and speeding up permitting processes. Voluntary bilateral or multilateral cooperation between the European countries on renewable electricity support schemes is, however, strongly encouraged by the Commission, and some countries - e.g., Belgium and the Nordic countries - have expressed interest in such schemes (e.g., Unger and Ahlgren, 2004; Söderholm, 2008; Verhaegen et al., 2007).

It should be clear that while the RES-E Directive sets the stage for a harmonized support scheme, it does not indicate a preferred type of mechanism other than that it needs to fulfill certain criteria (e.g., compatibility with the principles of the internal EU electricity market, simple and costeffective, etc.). As was noted above, today most European countries rely on either green certificate (quota-based) systems or on different types of feed-in laws. Nevertheless, in spite of the proved effectiveness of feed-in laws - most notably inducing substantial increases in wind power capacity in Denmark, Germany and Spain - the discussions about a harmonized support system have almost solely focused on quota systems with EU-wide tradable green certificates (Rowlands, 2005). ${ }^{1}$ Muñoz et al. (2007) note:

Quota support schemes were favored by DG Competition (Lauber, 2004), and often seen as more costefficient and in line with the EU single electricity market objectives than feed-in laws. An industry association was set up in 2001, RECS International, to experiment with [renewable energy certificates], establish standards and serve as an embryo for a future mandated European-wide certificate-based system. (p. 3105).

At the same time, it has often been claimed that harmonized feed-in laws are not feasible since it would be difficult to determine an adequate value for an EU-wide tariff. Muñoz et al. (2007) suggest, however, that the prospects for harmonizing feed-in law support schemes are brighter than often claimed, and they stress that attention should primarily be paid to the methodology used to calculate the support level rather than at identifying a specific uniform level. They therefore propose such a methodology for harmonization with a focus on a modular premium for renewable electric power.

With its explicit focus on harmonized feed-in laws, the Muñoz et al. (2007) (hereafter MOT) study is a welcome and interesting addition to the literature, not the least since

\footnotetext{
${ }^{1}$ See, however, Morthorst and Jensen (2006) for a recent exception.
}

it highlights a number of critical policy design issues that should be acknowledged for such a harmonized system to be efficient and legitimate. Nevertheless, a number of elements of their proposed methodology deserve further scrutiny, and this short paper aims at critically analyzing some of the economic efficiency and policy legitimacy issues that are raised by the MOT study. We highlight the choice between green certificate systems and feed-in laws, but focus in particular on the specific design of a harmonized feed-in law scheme.

This comment proceeds as follows. In Section 2 we briefly discuss the economic efficiency of different support systems, and we pay particular attention to the (realistic) case where the marginal costs of renewable electric power are uncertain. We do not attempt to argue that feed-in laws are inferior to green certificate systems or any other support system; our message is rather that different support systems to some extent face different challenges and their relative economic efficiency are affected by the shape of the marginal benefit- and cost-curves for renewable electricity. These issues deserve explicit attention in the policy strive towards harmonization across countries. Moreover, the nature of the benefits of renewable electricity promotion largely determines policy design. Section 3 outlines the MOT approach to feed-in law harmonization and comments on each of the elements of their methodology, while Section 4 provides some concluding remarks.

\section{The economic efficiency of harmonized support systems}

A given target for renewable electricity can be achieved in many ways, and on a general basis regulators can choose between volume support and price (cost) support. This section aims at illustrating the main differences between a green certificate system and feed-in tariffs (or, alternatively, a fixed premium scheme). We comment in particular on the economic efficiency of integrated support systems, and on how the nature of the costs and benefits of renewable electricity promotion affects policy design and outcome. ${ }^{2}$

A green certificate system typically involves an obligation for retailers to purchase a pre-determined amount of green electricity, $\bar{Q}_{G}$, often in practice expressed as a share of their total electricity sale. Each MWh green electricity produced in plants eligible for certificates yields one certificate that can be sold. In this way a market for the certificates is established; the demand is determined by the total quota and the power generators have an incentive to supply certificates since they thereby increase their revenues. The price of green certificates equals the premium unit revenue that renewable electricity producers must receive

\footnotetext{
${ }^{2}$ For simplicity, here we ignore the interactions with the conventional market for electricity. The price of green certificates or the level of fixed premium needed to reach required targets will be affected by the marginal cost of conventional electricity. For instance, if this latter cost increases the conventional electricity price, $P$, will increase, thus reducing the premium needed to fulfill any renewable electricity target.
} 
a

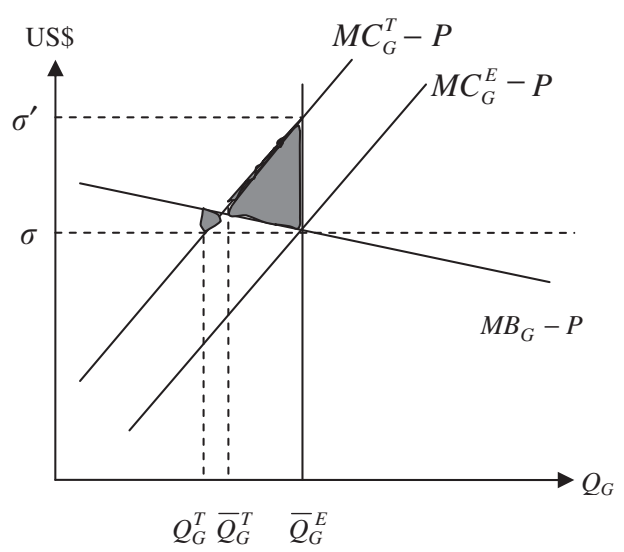

b

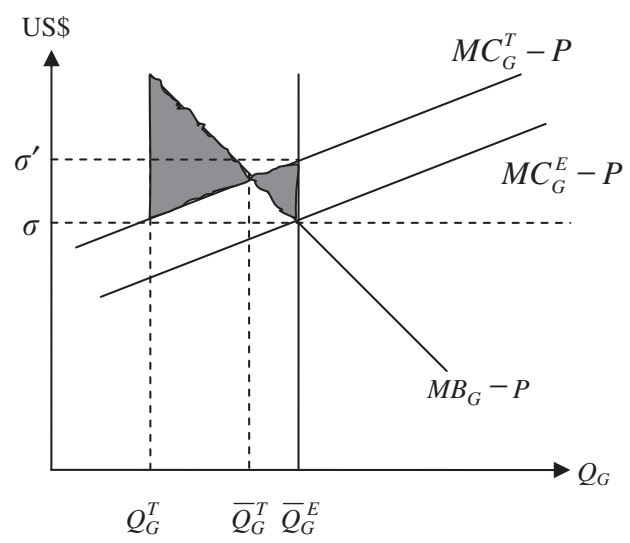

Fig. 1. The economic efficiency of renewable electricity support systems under uncertainty.

to fulfill the quota, and this premium will be determined in part by the marginal social cost of renewable electricity, $M C_{G}$. Alternatively, the regulator can introduce a pricebased support, either in the form of a feed-in tariff or a premium. In the former case, producers of renewable electricity sell at a pre-set price per $\mathrm{kWh}$ generated over a given time period, while in the latter case the producers sell at the conventional market price for electricity, $P$, and a premium is added to that price. The premium is also typically guaranteed for a given number of years.

It should be clear that if the regulator has complete knowledge about the marginal cost of producing renewable and conventional electricity (as well as of electricity demand), supporting renewable electricity through priceor quota-based mechanisms will generate equal outcomes. In such a situation it would be easy to determine the value of the feed-in or premium tariff to achieve a set target for renewable electricity. Alternatively, the same target could be combined with trade in green certificates, and the price of the certificate would then exactly equal the premium tariff (at least if ignoring potential differences in transaction costs). Thus, in the absence of any market uncertainty, the regulator would essentially remain indifferent between the two types of support mechanisms. Furthermore, both support systems would - in the presence of uniform premium levels across technologies and locations-promote a cost-effective implementation of a given production of renewable electricity.

Fig. 1 provides a framework for analyzing the economic efficiency of the two support mechanisms under regulatory uncertainty. ${ }^{3}$ An economically efficient public support of renewable electricity requires that the production of renewable electricity is at the level where the marginal social benefits equal marginal social costs. We assume here that the regulator can properly identify the marginal benefit of renewable electricity, $M B_{G}$, over and above that

\footnotetext{
${ }^{3}$ The analytical model presented here is heavily based on Carlén et al. (2005) and Carlén (2006).
}

generated through the contribution of green electricity to the conventional electricity market, $P$. In the RES-E Directive several political ambitions are provided as arguments for an increased reliance on electricity produced by renewable energy sources. These include, first and foremost, improved security of supply in the Union, but also social cohesion, local employment opportunities and environmental protection are put forward as arguments. The exploitation of renewable energy sources will also, it is argued, make it easier to fulfill the Union's Kyoto commitment more rapidly, but this constitutes essentially only a secondary goal of the Directive. We will return to the benefit component of green electricity promotion below, but for now we simply assume that the marginal benefit curve is known with certainty.

We assume, however, that the regulator has incomplete knowledge about the marginal cost of producing green electricity, and thus about the exact premium, $\sigma$, needed to achieve a given target. The marginal cost curves (minus expected electricity price levels) that are displayed in Fig. 1 represent the horizontal sum of the respective countryspecific marginal cost curves. These costs include both private and external costs, the latter to some extent being internalized by existing permitting processes and other policy instruments. We make a distinction between the expected marginal cost curve, $M_{G}^{E}$, and the true marginal cost curve, $M_{G}^{T}$. Based on these assumptions we can now identify two different situations, one in which the marginal benefit curve is fairly flat and the marginal cost curve is relatively steep (see graph (a)) and one where the opposite is true (see graph (b)). As shown in the seminal study by Weitzman (1974), the relative slopes of these curves will influence the expected efficiency of price- versus quantitybased policies.

This can be shown by first noting that in each of the graphs displayed in Fig. 1, the regulator assumes that $\bar{Q}_{G}^{E}$ represents the efficient level of renewable electricity production. In practice, however, the true marginal cost is higher than expected, and the efficient level of $Q_{G}$ is 
therefore lower, i.e., $\bar{Q}_{G}^{T}$. If the regulator uses a feed-in premium scheme to achieve the $\bar{Q}_{G}^{E}$ target, the level of the premium will bet set at $\sigma$. However, at this support level only $Q_{G}^{T}$ units of renewable electricity will be produced, but since all countries face the same support premium, production will primarily take place in low-cost countries. The difference between the actual and (true) optimal level of production leads to an efficiency loss, which equals the area represented by the left triangle in graph (a). If instead a green certificate scheme is implemented, the quota obligation would be set at $\bar{Q}_{G}^{E}$, and this determines the actual production level (i.e., $Q_{G_{E}}=\bar{Q}_{G}^{E}$ ). The price of green certificates needed to achieve $\bar{Q}_{G}^{E}$ will be $\sigma^{\prime}$, which is higher than the fixed premium chosen by the regulator in the feedin law case. The higher-than-expected marginal cost of producing renewable electricity implies that actual production is higher than the efficient level, resulting in an efficiency loss equaling the right shaded area in the graph (a). This example shows that with a flat marginal benefit curve and a steep marginal cost curve, a quantity-based scheme will generate a higher efficiency loss than a pricebased scheme. In Fig. 1(b) the situation is the reversed, and here the opposite conclusion is reached. Thus, in the presence of regulatory uncertainty about the marginal costs of producing renewable electricity, economic efficiency of the two types of support systems will depend on the relative slopes of the marginal benefit and marginal cost curves. ${ }^{4}$

Although the MOT study considers both the benefit and the cost sides of renewable electricity production, the above considerations are largely downplayed in their approach to feed-in law harmonization. The assessment of the $M C_{G^{-}}$ curve is critical for identifying an efficient support mechanism for renewable electricity. For instance, if the marginal cost curve is flat (which some analysts argue, e.g., Jansen, 2003), this would speak in favor of a quantitybased approach. The shape of the marginal benefit curve also plays a role here, and this makes it important to identify both the relevant types of benefits involved as well as the marginal value of these benefits at different levels of renewable electricity production. Below we argue that there may exist a case for expecting a rather flat marginal benefit curve in the case of renewable electricity in Europe, thus speaking in favour of a feed-in law scheme. It should also be clear that in Fig. 1 we assume that the benefit to society of one extra unit of renewable electricity production is equal across all countries, i.e., benefits are assessed at the EU level rather than at the national or local levels. This notion differs, as we will see below, from that employed in the MOT approach to harmonization, which builds on the assumption that the marginal benefit of renewable electricity production has major local components. We elaborate more on this difference in the next section.

\footnotetext{
${ }^{4}$ Uncertainty about the position of the marginal benefit curve will also lead to efficiency losses, but the magnitudes of these losses will not differ depending on the support scheme chosen. Thus, the choice between priceand quantity-based policy instruments is not affected by such uncertainty.
}

\section{The MOT harmonized feed-in scheme for renewable electricity}

As was noted above, the MOT approach to feed-in law harmonization builds on a premium scheme, and the starting point is not to identify a unilateral premium but rather a methodology that can be used to calculate countryspecific premiums. In this approach renewable electricity producers receive the conventional electricity market price plus a premium, $\sigma$, which in turn is made up of four main components so that

$\sigma=\underbrace{\text { investment }+ \text { grid services }+ \text { EU political incentive }}_{\text {harmonized across countries }}+$ national,

where the first three components are to be harmonized across countries, while the last component allows for national priorities. The total premium "varies for each country and technology, and is adjusted over time [but remains] constant for any particular installation in order to reduce uncertainty on future revenue flows [...]," (Muñoz et al., 2007, p. 3108). Let us proceed by focusing first on the three types of harmonized components.

\subsection{The harmonized components}

The investment component aims at providing some basic cost recovery for investments in renewable electric power plants. It is suggested that this component is revised in 4-year periods to reflect cost reduction due to technological innovation. Such revisions reduce the value of the rents retained by renewable electricity producers. A related system of downward adjustment already exists in Germany, but in this case the regulators rely on fixed degression rates, while in the MOT approach past cost reductions form the basis for revisions undertaken every fourth year. Added to the investment component in the total premium is an additional policy incentive, which is linked to the targets in the EU Directive. While the investment component will differ across technologies, one can choose to let the policy component be the same across all renewable electricity technologies.

Although the investment component is to be harmonized it should be clear that cost recovery implies different levels in different countries, depending, for instance, on the availability of biomass, wind conditions, etc. It remains unclear how countries can come to an agreement on this component. The MOT study proposes that assessment of "the cost curve should be done at the sector level based on industry data, preferably using international figures," (Muñoz et al., 2007, p. 3111). However, the above appears to rely heavily on an engineering cost view, i.e., the idea that cost is an attribute of a specific technology rather than an attribute of the context within which the technology is applied. This is, we argue, only in part a valid assumption. In other words, although, say, wind turbines are sold in an international market, it is very difficult to assess the cost of 
wind power since ultimately the local context will heavily determine costs and thus the needed premium for cost recovery. This also means that in practice it is hard - and even meaningless - to make a distinction between an investment and a policy incentive component. In a feedin premium it is "only" essential to make an appropriate assessment of the marginal cost curve $M C_{G}$, and this assessment must include both those cost attributes that are essentially the same across all countries (e.g., the cost of a wind turbine) and those that are more site- as well as country-specific (e.g., wind conditions, transport infrastructure, etc.). Clearly, this shows the importance of marginal cost uncertainty on the part of policy makers. The MOT approach risks leading policy makers astray from the real-life conditions that investors face at actual sites. Ignoring the assessment of real-life costs can, in the presence of uncertainty, either lead to poor goal fulfillment or to creation of substantial producer rents. Depending on the slope of the marginal cost curve, it can even make feedin laws inefficient compared to green certificate systems.

Moreover, the MOT approach to reducing premiums is interesting and innovative but it risks being cost-ineffective. The reason is that two plants, one built 4 years before the other, will receive different marginal revenues. While this may not be a big problem for non-dispatchable renewable electricity (e.g., wind power), it will reduce the costeffectiveness of the use of, for instance, bio-fuelled power plants. Furthermore, if technical progress occurs rapidly this premium-reduction scheme may even induce producers to avoid scrapping older and more inefficient plants.

The last component of the harmonized premium comprises compensation to renewable electricity whenever it provides "grid services which are not explicitly reflected in electricity prices," (Muñoz et al., 2007, p. 3109). Examples include grid stability and sustaining of tension gaps. Although it is clear that expanded renewable electricity production may generate such public goods, it is not evident that this should form part of a policy based on the RES-E Directive outlining specific goals for renewable electricity production. As long as the general premium is set an appropriate level these targets will be met and any benefits to the grid would follow. If additional measures to produce grid services are deemed necessary, these should preferably form part of another tailor-made policy package.

In sum, although the MOT study raises a number of important issues, their methodology for harmonizing feedin premiums become unnecessarily complicated, fails to promote cost-effectiveness and tends to distract from the importance of assessing EU-wide marginal cost curves for renewable electricity (both their position and their shape). The main idea between harmonized support systems is really to exploit cost differences across countries, but if premiums are allowed to vary across technologies - and even across different plants of a given technology due to the premium revision mechanism-this will not be achieved. Our point is not that cost-effectiveness always should be a policy priority — often there may exist a conflict between policy legitimacy and cost-effectiveness (e.g., Söderholm, 2008) - but we simply note that if we do not consider cost-effectiveness to be important it does not make much sense at all to discuss harmonized support systems.

\subsection{The national component}

In the MOT approach, the national component is included in the total premium to account for any national or regional priorities. It should be made clear that this component of the premium focuses mainly on the benefit side of renewable electricity production and does not address the national cost differences that were stressed in the previous sub-section. National benefits may include local employment and environmental benefits (e.g., avoided local pollutants). In the MOT study, the authors note that this is in line with the RES-E Directive, which explicitly points out social cohesion, employment and environmental benefits as arguments for the promotion of renewable electricity. Thus, since the perception of these benefits can differ substantially across countries this also means that the premium will differ. ${ }^{5}$

Again, this will reduce the cost-effectiveness of the policy. If national priorities should be addressed explicitly in this way, why not simply abandon the harmonization idea from the start and leave it to the national governments to ensure compliance with the national targets? In the end this boils to the question of how one should interpret the RES-E Directive. There exist two alternative views here. First, the interpretation that we make in our analysis related to Fig. 1 is that the Directive states a specific goal for renewable electricity production-i.e., 21 percent of renewable electricity by the year 2010 - and regardless of which policy instrument that is chosen, this is the goal against which the policy should be evaluated. This also implies that one additional MWh of renewable electricity incurs the same benefit regardless of location and start-up year. The main motive behind the Directive is security-of-supply benefits but, as noted above, also other motives such as social cohesion and employment play a role. Thus, these are reasons for promoting renewable electricity but should not influence the design of the policy needed to fulfill the stated goal of 21 percent renewable electricity. With this interpretation cost-effectiveness implies that a specific level of renewable electricity production should be met at minimum cost, and this can only be achieved if premium levels are the same across all technologies and countries.

The second interpretation, implicitly the one adopted in the MOT study, is that any policy should directly aim at

\footnotetext{
${ }^{5}$ In the MOT study, it is argued that as national electricity markets converge over time, so would the premiums used for renewable electricity. However, it is hard to see why national priorities concerning employment and local environmental impacts would converge just because electricity markets converge.
} 
internalizing the benefits of renewable electricity production, and since these differ across countries, the premium levels must also vary. In this setting, cost-effectiveness is essentially replaced by a criterion stating that premium levels should be designed so that the marginal benefits of renewable electricity production is the same across all locations. This would (theoretically at least) minimize the cost of achieving a certain benefit of renewable electricity (rather than a certain production level). ${ }^{6}$

In order to understand the difference between these two interpretations it is useful to draw a parallel to a common distinction made in the environmental economics literature, namely that between uniformly mixed and nonuniformly mixed pollutants. For the former type of pollutant the environmental damages are the same regardless of where the emissions take place (e.g., carbon dioxide), but for the latter type the damages differ, for instance, due to the receiving environment's conditions (e.g., sulfur dioxide). For uniformly mixed pollutants, uniform taxes are sufficient to achieve a cost-effective reduction in damages, but for non-uniformly mixed pollutants only differentiated tax levels can cost-effectively achieve certain damage reductions.

At first glance this seems to support the MOT approach to feed-in law harmonization, but this presumes that the national benefits identified in the RES-E Directive in themselves constitute a valid basis for designing a renewable electricity promotion policy. This is not at all evident. Instead a reasonable principle for any harmonized support scheme, we argue, is that the policies that are implemented to internalize the external benefits of renewable electricity (or alternatively the external costs of fossil-fueled electricity) should be as neutral from a competitiveness point of view as possible. For instance, in the case of an integrated green certificates market the certificate price will be equal in all countries taking part, also implying that the marginal social benefits attached to the "green" component of electricity production do not differ with respect to its national origin. This means that the countries will have to give up some of the national goals that often are associated with the expansion of renewable electricity production. We suggest that this should not be perceived as a major sacrifice from a policy perspective. ${ }^{7}$ There are a number of reasons for this claim:

- In reasonably well-integrated electricity markets, the "portfolio" of electric power plants does not provide services to the consumers of a specific nation but to the electricity consumers of the greater region. Besides, many of the environmental benefits of increased renew-

\footnotetext{
${ }^{6}$ Still, the fact that the MOT approach relies on various support levels for the same technology but of different vintages makes it inefficient even if one can properly differentiate support levels based on national benefits.

${ }^{7}$ At the same time, the rationale behind the 'decoupling' of national and local goals from the functioning of a certificate system represents a pedagogical challenge for responsible politicians and the authorities involved.
}

able electricity production are cross-boundary (e.g., reduced sulfur emissions).

- The main motive behind renewable electricity promotion in the RES-E Directive is security of supply. However, this policy goal should also be considered from a European (rather than from a national) perspective. Interruptions in one country's electricity distribution will affect consumers in other countries, and any measures to increase security of supply will incur spillover effects and positively influence the entire consumer community. European coordination of measures aimed at increasing the security of supply will thus be efficient and help in avoiding the use of sub-optimal solutions.

- Public investments are often motivated by the presence of employment and industrial policy benefits, but this motive is not particularly convincing. High unemployment and large exports are primarily macroeconomic issues that cannot (in the long run) be solved by allocating public funds to selected sectors of the economy, but rather by addressing specific market failures in the labor market and/or through specific regional policy measures. Moreover, it is far from certain that the combination of labor market policies and energy policy measures is the most effective way of reducing unemployment. All public investments spur employment (in the short run), but resources used for renewable energy projects may not necessarily be wellspent money to achieve this target. Moreover, it is hard to see why renewable electricity should be subsidized on these grounds; ${ }^{8}$ a multitude of measures can spur local employment including investment in fossil-fueled power plants.

- An increase in the use of renewable electricity also means that the emissions of local pollutants (e.g., particulates) from fossil-fueled electricity can be avoided. However, this benefit of renewable electricity promotion will not risk disappearing if the support system is internationalized with uniform support levels. The reason is simply that any capacity addition in a specific country lessens the need for (eventually "dirty") capacity expansions in an adjacent country (if the two countries' electricity markets are integrated). In other words, diverting all new wind power investments to Norway does not imply that the Swedes begin to experience more severe health problems due to increases in local pollutants.

There are other problems connected with basing a harmonized feed-in law scheme on the above types of local impacts. One relates to the fact that one may question

\footnotetext{
${ }^{8}$ It should be clear that local employment in remote regions with high unemployment rates may increase with the investment in renewable electricity, but it is one thing to note that this is a side-benefit of the renewable energy policy and another thing to claim that this should influence both the design and the evaluation of that same policy.
} 
to what extent these impacts are correlated with the level of renewable electricity production (i.e., with $Q_{G}$ in Fig. 1). For instance, in the case of local employment the impacts are more pronounced at the investment stage, but as production starts the benefits are substantially lower. This also suggests that the $M B_{G}$-curve may be rather steep for (at least some of) these types of national and local impacts, speaking thus in favor of a quota-based system. In contrast, we would argue that the international (EU-wide) marginal benefits of renewable production, most notably improved security-of-supply, would be more constant over the range of renewable electricity production (i.e., a flatter $M B_{G}$-curve). Carlén et al. (2005) make the same argument for the case where the Union's member states use renewable electricity promotion to reduce the costs of complying with the burden-sharing agreements under the Kyoto Protocol. Also here the $M B_{G}$-curve becomes rather flat and it is located at the level of the price of carbon emission allowances in the European trading system. In sum, a stronger focus on the cross-border benefits (and thus less focus on local impacts) may strengthen the case for using feed-in law schemes rather than green certificate systems.

Furthermore, some of our arguments above rely on the assumption that we have fairly well-integrated electricity markets, but we think this is a relevant assumption because if this is not the case it does not make much sense to discuss harmonized support schemes at all. In addition, evolution of a common framework for the support of renewable electricity is likely to be characterized by a combination of top-down policy targets and bottom-up achievements by separate countries. Just as in the case of currency standards a small group of countries may take the lead and a standardized approach is evolved by example and learning experiences are gained as the core group becomes more inclusive. As time lapses, more countries join "in response to self-interest, persuasion, or perhaps subtle coercion," (Ellerman, 2000). The speed of this development is likely to be determined by the development of integrated markets for conventional electricity in the European Union.

\section{Concluding remarks and implications}

Muñoz et al. (2007) present an interesting methodology for designing a harmonized feed-in law scheme for renewable electricity in the European Union. In this comment we have argued that this approach tends to ignore many of the practical difficulties in assessing the real costs of renewable electricity, and it builds on an interpretation of the EU Renewables Directive that in essence implies that harmonized support systems are of little value. Their approach attempts to use one policy instrument to achieve a number of policy goals at the same time; as argued already in the early 1950s by the Dutch economist Jan Tinbergen this is likely to be an inefficient policy approach (e.g., Tinbergen, 1952). The best approach is to apply one policy instrument for one policy goal. In the RES-E Directive, the specific production targets for renewable electricity represent the relevant policy goal.

It should be clear that the implementation of harmonized support schemes for renewable electricity in Europe constitutes a great challenge regardless of the support scheme chosen. Muñoz et al. (2007) rightly stress that if we believe that harmonization is worthwhile, feed-in laws should also be seriously considered and many of the arguments put forward against feed-in laws lack empirical evidence. However, if the Union decides to go along this policy path we believe that there is a strong case for disregarding the specific national benefits of renewable electricity production in the design of harmonized support systems, and instead seriously consider international - perhaps at the start bilateral - policy support coordination based on entirely uniform support levels. If this cannot be achieved, it is better to keep the present system of national tailor-made support schemes, and take comfort in the fact that both feed-in laws and green certificate systems are compatible with EU state-aid and competition rules.

\section{Acknowledgments}

The research undertaken in preparation of this paper has been funded by the project "Pathways to Sustainable European Energy Systems", hosted by Chalmers University of Technology (with Vattenfall as the main funder). Valuable help and encouragement from Bo Rydén and Filip Johnsson are gratefully acknowledged. Any remaining errors, however, reside solely with the author.

\section{References}

Carlén, B., 2006. A comparative analysis of policy instruments promoting green electricity under uncertainty. Mimeo, available at $\langle$ www.nordicenergyperspectives.org $\rangle$.

Carlén, B., Mandell, S., Carling, A., 2005. Svensk klimatpolitik under nationellt usläpp-smål respektive avräkningsmål, ER 2005:29, Eskilstuna, Sweden.

Del Rio, P., 2005. A European-wide harmonised tradable green certificate scheme for renewable electricity: is it really so beneficial? Energy Policy 33, 1239-1250.

Directive 2001/77/EC of the European Parliament and of the Council of 27 September 2001 on the promotion of electricity produced from renewable energy sources in the internal electricity market, Brussels.

Ellerman, A.D., 2000. Tradable Permits for Greenhouse Gas Emissions, Report No. 69, MIT Joint Program on the Science and Policy of Global Change. Massachusetts Institute of Technology, Cambridge, USA.

European Commission, 2005. The Support of Electricity from Renewable Energy Sources, Communication COM(2005) 627, Brussels.

Huber, C., Faber, T., Resch, G., 2006. Prospects of renewable energy development in the European electricity sector: results of the simulation tool green-X. Energy \& Environment 17 (6), 929-950.

Jansen, J.C., 2003. Policy Support for Renewable Energy in the European Union: A Review of the Regulatory Framework and Suggestions for Adjustment. ECN-C-03-113, Energy Research Centre of the Netherlands, Petten, The Netherlands. 
Lauber, V., 2004. REFIT and RPS: options for a harmonised community framework. Energy Policy 32, 1405-1414.

Midttun, A., Koefoed, A.L., 2003. Greening of electricity in Europe: challenges and developments. Energy Policy 31, 677-687.

Morthorst, P.E., Jensen, S.G., 2006. Coordinated renewable energy support schemes. Energy \& Environment 17 (6), 869-884.

Muñoz, M., Oschmann, V., Tàbara, J.D., 2007. Harmonization of renewable electricity feed-in laws in the European Union. Energy Policy 35, 3104-3114.

Rowlands, I.H., 2005. The European Directive on renewable electricity: conflicts and compromises. Energy Policy 33, 965-974.

Söderholm, P., 2008. The political economy of international green certificate markets. Working Paper, Economics Unit, Luleå University of Technology, Sweden.

Tinbergen, J., 1952. On the Theory of Economic Policy. North Holland, Amsterdam.
Unger, T., Ahlgren, E., 2004. Impacts of a common green certificate market on electricity and $\mathrm{CO}_{2}$ emission markets in the Nordic countries. Energy Policy 33 (16), 2152-2163.

Verhaegen, K., Meeus, L., Belmans, R., 2007. Towards an international certificate system - the stimulating example of Belgium. In: Deketelaere, K., et al. (Eds.), Critical Issues in Environmental Taxation: International and Comparative Perspectives, vol. 4. Oxford University Press, New York, pp. 455-470.

Voogt, M.H., Uyterlinde, M., de Noord, K., Skytte, L. H., Nielsen, M., Leonardi, M., Whiteley, M., Chapman, 2001. Renewable Energy Burden Sharing-REBUS - Effects of Burden Sharing and Certificate Trade on the Renewable Electricity Market in Europe, ECN-C-01-030, Petten, The Netherlands.

Weitzman, M.L., 1974. Prices vs. quantities. Review of Economic Studies $41,447-491$ 